\title{
POSITIVISMO JURÍDICO Y RAZÓN PRÁCTICA. REFLEXIONES SOBRE UN TEXTO DE ALEJANDRO SAHUÍ MALDONADO'
}

LEGAL POSITIVISM AND PRACTICAL REASON. REFLECTIONS ON A TEXT BY ALEJANDRO SAHUÍ MALDONADO

José Manuel Cabra Apalategui ${ }^{2}$

RESUMEN: En "Positivismo y concepción argumentativa del Derecho. Un alegato a favor de su compatibilidad", Alejandro Sahuí Maldonado aborda muchas de las cuestiones que han centrado el debate iusfilosófico contemporáneo desde la irrupción de las teorías de la argumentación jurídica; a saber: el concepto de justificación, la conexión entre derecho y moral, el principio de unidad de razonamiento práctico o las relación entre metaética y teoría del derecho. Este trabajo analiza críticamente las tesis mantenidas por Sahuí, especialmente, su intento de fundamentar la normatividad del derecho conjugando la tesis de la separación entre derecho y moral y la tesis de la relevancia práctica del derecho.

Palabras clave: Argumentación jurídica, positivismo jurídico, razón práctica, normatividad, justificación.

Aвstract: In his work "Positivism and Argumentative Conception of Law. A Plea for its Compatibility", Alejandro Sahuí Maldonado deals with some of the issues that have dominated the legal philosophical debate since the appearence of the theories of legal argumentation; namely: the concept of justification, the

1 Este trabajo se enmarca en el proyecto de investigación "CONFLICTOS DE DERechos: Tipologías, RAZONAmientos, DEcisiones" (DER2016-74898-C2-1-R) del Ministerio de Economía y Competitividad / AEI y FEDER.

2 Licenciado en Derecho por la Universidad de Málaga. Doctor por la Universidad Carlos III de Madrid. Especialista universitario en Argumentación Jurídica por la Universidad de Alicante. Profesor de Teoría y Filosofía del Derecho en la Facultad de Derecho de la Universidad de Málaga. Autor de Racionalidad y Argumentación jurídica en Aulis Aarnio (2000) y Sobre Derecho y Argumentación (2015). <jcabra@uma.es>. 
connection between law and morality, the principle of the unity of practical reason or the relationship between meta-ethics and legal theory. This paper critically analizes the thesis defended by Sahuí, specifically, his intend of founduing the normativity of law connecting both the thesis of separation between law and morals and the thesis of the practical relevance of law.

KEYWORDS: Legal reasoning, legal positivism, practical reason, normativity, justification.

SUMARIO: I. Introducción; II. El modelo deductivo en la aplicación del derecho; III. La tesis de la separación conceptual entre derecho y moral; IV. El principio de unidad de razón práctica; V. Metaética y Teoría del derecho; VI. Positivismo jurídico y la concepción argumentativa del derecho.

\section{INTRODUCCIÓN}

7 ste trabajo tiene su origen en los comentarios informales que hice a un texto de Alejandro Sahuí Maldonado cuando aún no había sido publicado. ${ }^{3}$ En dicho texto, y a propósito de las tesis de Eugenio Bulygin y las discusiones mantenidas entre al profesor argentino y sus críticos, Sahuí aborda con voz propia muchas de las cuestiones que han centrado el debate iusfilosófico contemporáneo desde la aparición de las teorías de la argumentación jurídica: la idea de justificación, la conexión entre derecho y moral, el principio de unidad de razonamiento práctico o las relación entre metaética y teoría del derecho. Sahuí no se limita a exponer y comentar las tesis de Bulygin y sus críticos, sino que se sirve de ellas para tomar partido abiertamente, con un claro objetivo: fundamentar la normatividad del derecho desde una posición positivista, y más concretamente, desde el positivismo metodológico. El intento

3 Hoy puede verse en Sahuí Maldonado, Alejandro, "Positivismo y concepción argumentativa del Derecho. Un alegato a favor de su compatibilidad", en Maurízio Zanotelli (Coord.) Teoría de la argumentación jurídica, Guritiba, Juruá, 2015, pp. 51-81. 
de conjugar la tesis de la separación entre derecho y moral y la relevancia práctica del derecho constituye, en mi opinión, la aportación más valiosa de este texto. Los comentarios que siguen pretenden, unas veces, intentar clarificar los términos de la discusión, y, otras, cuestionar las tesis mantenidas por el autor; en ningún caso, sin embargo, pueden verse como alegato antipositivista. Sigo aquí el orden en que están tratadas estas cuestiones en el texto de Sahuí. Espero que estas reflexiones estén a la altura de aquellas que las motivaron.

\section{El modelo deductivo en la aplicación del derecho}

La primera cuestión que se plantea es la idoneidad del modelo del silogismo jurídico. Creo que nadie hoy día pone en duda que el razonamiento jurídico (en realidad, cualquier razonamiento) tiene una estructura formal lógica, al menos en el sentido en que aquí se plantea. ${ }^{4}$ Con independencia de otros aspectos - pragmáticos, retóricos, etc.-, que pertenecen a la llamada justificación externa, un razonamiento no es válido si no está justificado internamente, esto es, si la conclusión no puede ser presentada como una inferencia válida resultante de un conjunto más o menos amplio de premisas dadas, una de las cuales es una norma general. El llamado contexto de descubrimiento puede resultar interesante desde otros puntos de vista (así, la retórica, la teoría de la acción, la neurociencia, etc., tienen en común el de atender a diversos aspectos fácticos o psicoló-

4 No es pacífico en la doctrina que la relación entre las premisas y la conclusión de un razonamiento sea una relación de deducibilidad (vid. sobre esta cuestión Bayón Mohino, Juan Carlos, "Bulygin y la justificación de las decisiones judiciales: la parte sorprendente", en José Juan Moreso y María Cristina Redondo (eds.) Un diálogo con la teoría del derecho de Eugenio Bulygin, Barcelona, Marcial Pons, 2007, pp. 137-152.). Aquí la referencia a la estructura formal lógica del razonamiento no pretende determinar el tipo de relación existente entre las premisas y la conclusión (lógica, semántica), sino algo más impreciso, como es el carácter normativo de la inferencia que conduce a la conclusión. 
gicos de la práctica argumentativa), pero no desde el punto de vista de la justificación de las decisiones jurídicas.

Como se apunta en el texto de Sahuí, la asunción del modelo silogístico tiene implicaciones valorativas que conectan con los principios liberales del imperio de la ley y división de poderes. ${ }^{5}$ En un sentido más abstracto aún, la aplicación de normas abstractas y generales, sean jurídicas o no, a casos particulares supone ya la realización del principio de universalidad, a saber: tratar de igual manera los casos iguales (aquellos que presentan las propiedades relevantes contenidas en la condición de aplicación de la norma). Éste es un principio general de la racionalidad que tiene su equivalente jurídico-político en la igualdad de trato, sin embargo, los principios de imperio de la ley y división de poderes son principios políticos que van más allá de la estructura lógica del razonamiento. Ciertamente, el imperio de la ley contiene ya el principio de universalidad, en el bien entendido de la ley como prescripción general y abstracta: la consecuencia de la aplicación de una norma general es que todos los casos relevantes son tratados de igual forma. Ahora bien, lo importante aquí es que los principios mencionados no se limitan a establecer que la conclusión debe derivarse de las premisas, sino de qué premisas debe derivar la conclusión para que pueda tenerse como justificada: del derecho dictado por el poder legislativo. Y esto ya no es una cuestión lógica o formal.

En este sentido, habría que distinguir, como hacen Koch y Rußmann, entre el postulado de vinculación a la ley (Gesetzbindungspostulat) y el postulado de la deductividad (Deduktivitatspostulat). ${ }^{6} \mathrm{El}$ primero es un principio político que afecta a la obtención de la premisa normativa; el segundo, un principio racional relativo a la estructura

5 Laporta, Francisco, "Para Eugenio Bulygin”, en José Juan Moreso / María Cristina Redondo (eds.) Un diálogo con la teoría del derecho de Eugenio Bulygin, op. cit., pp. 33-37, en lo que aquí interesa, p. 36.

6 Koch, Hans-Joachim y Helmut Rußmann, Juristische Begründunslehre. Eine Einführung in Grundprobleme der Rechtswissenschaft, München, Beck, 1982, p. 112. 
interna del razonamiento justificatorio. El postulado de la deductividad es condición necesaria, pero no suficiente para la realización del postulado de vinculación a la ley; en efecto, sólo cuando sus decisiones pueden justificarse como la aplicación de normas positivas generales a casos particulares, esto es, cuando se deducen (o, en un sentido más amplio, se infieren) de aquellas, decimos que los jueces se someten a la ley. Esta es la relación que existe entre el modelo subsuntivo, que hace referencia a la estructura del razonamiento, y los principios liberales defendidos por Bulygin, que tienen que ver con el tipo de premisas susceptibles de justificar una decisión jurídica; o si se quiere, la relación entre la lógica y la política.

En este apartado, Sahuí se hace eco de las observaciones críticas de Manuel Atienza y Juan Carlos Bayón. Mientras que las del primero parecen dirigidas a la dimensión de la deductividad, mostrando las insuficiencias, que no las deficiencias, del modelo silogístico, ${ }^{7}$ las de Bayón, en cambio -si no he entendido mal- parecen ir dirigidas al segundo aspecto, el de la vinculación a la ley, al atribuir a este modelo la presunción de que el derecho puede proporcionar para cada caso una premisa normativa acabada y definitiva - una regla-, así como sus criterios de aplicación. ${ }^{8}$ A mí me parece que el modelo deductivo defendido por Bulygin va más en la línea apuntada en el párrafo anterior, es decir, que la subsunción es condición necesaria, aunque no suficiente de la realización de ciertos principios políticos. Obviamente, no podemos descartar los

7 "Lo que aporta la concepción formal (el estudio de los esquemas - de las formas- de los argumentos) es, sin duda, muy importante, pero también es muy imporante lo que deja fuera (el estudio de los aspectos materiales y pragmáticos de la argumentación)" (vid. Atienza, "Eugenio Bulygin y la teoría de la argumentación jurídica”, en José Juan Moreso y María Cristina Redondo (eds.) Un diálogo con la teoría del derecho de Eugenio Bulygin, op. cit,. pp. 39-49, aquí p. 45).

8 Bayón Mohino, op. cit., pp. 148 y ss. 
casos difíciles - tampoco lo hace Bulygin,$-{ }^{9}$ en los que los principios de vinculación a la ley y la separación de poderes pueden realizarse sólo parcialmente. En estas situaciones, lo único que podemos esperar de los jueces (ya que no una completa sujeción a la ley, en tanto que el derecho no proporciona una norma general inequívocamente aplicable) es que sus decisiones puedan presentarse ex post como un razonamiento deductivo. Ello significa, por un lado, que la decisión se infiere lógicamente de las premisas y, por otro lado, que la justificación deberá hacer explícitas el mayor número posible de premisas del razonamiento que permitan arribar a la decisión en cuestión. ${ }^{10}$ Sólo así es posible controlar y someter a juicio crítico las decisiones de los tribunales, especialmente en los casos difíciles. En definitiva, no creo que pueda ponerse en duda -tampoco es esa la intención de las observaciones de Atienza o Bayón- el valor de la lógica en el razonamiento jurídico, aun sosteniendo la importancia de esos otros aspectos (pragmáticos, retóricos, etc.) que forman parte de las prácticas argumentativas de los juristas.

\section{LA TESIS DE LA SEPARACIÓN CONCEPTUAL ENTRE DERECHO Y MORAL}

Mayor enjundia tiene la cuestión que es tratada en el segundo apartado, la tesis de la separación entre el derecho y la moral. Como es sabido, el positivismo jurídico metodológico sostiene la independencia conceptual entre la validez jurídica y la validez moral de una norma, es decir, que la corrección moral no es condición necesaria

9 Bulygin, Eugenio, "Manuel Atienza: análisis conceptual versus teoría de la argumentación jurídica”, en en José Juan Moreso / María Cristina Redondo (eds.) Un diálogo con la teoría del derecho de Eugenio Bulygin, op. cit,. pp. 173-180, aquí p. 175.

10 Esto es lo que se ha denominado "requisito de saturación" de un razonamiento (vid. Alexy, Robert, Teoría de la argumentación jurídica. La teoría del discurso racional como teoría de la fundamentación jurídica (trad. Manuel Atienza e Isabel Espejo), Madrid, Centro de Estudios Constitucionales, 1997, pp. 229, 236). 
ni suficiente de la validez jurídica. Tal y como apunta Sahuí, para la concepción argumentativa del derecho la conexión importante entre el derecho y la moral no está en el plano conceptual, ${ }^{1}$ sino en el plano de la justificación; en otras palabras, desde el punto de vista de la concepción argumentativa del derecho, la discusión relevante no gira en torno a la validez de las normas, sino acerca del carácter formal o material de la justificación jurídica: ¿es suficiente para tener una decisión jurídica como justificada que la premisa normativa del razonamiento justificatorio sea una norma jurídica válida (concepción formal) o es necesario que, además, sea aceptable moralmente (concepción material)? Esta cuestión conduce, por de pronto, al problema de la normatividad del derecho, esto es, a la cuestión de si las normas jurídicas válidas constituyen razones para la acción.

En contra de lo que sostienen Atienza, Nino, e incluso el mismo Bulygin, Sahuí rechaza que la normatividad sea una propiedad exclusiva de las normas morales y que, por tanto, sean éstas las únicas que pueden constituir auténticas razones para la acción. Por el contrario, defiende una normatividad genuinamente jurídica.

En la defensa de dicha tesis pueden identificarse, al menos, dos líneas de argumentación: una, que intenta explicar en qué podría consistir o, más bien, cuál sería el fundamento de la normatividad del derecho; y otra, dirigida a cuestionar la normatividad de la moral. El primero de los argumentos a favor de una normatividad específicamente jurídica es el siguiente:

[...] cabe pensar que cualquier defensor del positivismo metodológico, cuando se desempeña en calidad de agente que ha de tomar una posición personal frente a las normas jurídicas -y en algún

11 A pesar de que autores que sostienen abiertamente una concepción argumentativa, como Atienza o Alexy, mantengan una conexión conceptual, adoptando más o menos explícitamente la fórmula Radbruch (vid. Radbruch, Gustav "Gesetzliches Unrecht und übergesetzliches Recht", en Id. Gesamtausgabe (Bd. 3), Heidelberg, G.F. Müller, 1990, pp. 83-93; en especial, p. 89). 
momento debe hacerlo- puede proceder creyendo o no en ellas. Si el propio Bulygin no tuvo reparo en admitir que su noción de justificación a partir del silogismo subsuntivo deriva de una filosofía política liberal democrática, no habría problema por asumir que un positivista metodológico pudiese derivar su deber interno de obedecer el derecho a partir de valores y principios público-políticos, y no morales. ${ }^{12}$

Este argumento plantea algunas cuestiones importantes. Cabría preguntarse si lo que se denomina como principios público-políticos, ya se trate de los principios liberales de los que se ha hablado páginas atrás o de otros principios políticos, pertenecen o integran una categoría completamente independiente de la moral. ${ }^{13}$ Podría ser que Bulygin esté pensando en estos principios formales -imperio de la ley, separación de poderes o respeto del legislador democráti$\mathrm{CO}^{-}$como principios morales en un sentido amplio. Esto daría pleno sentido a la afirmación de Bulygin de que la normatividad jurídica depende en última instancia de razones morales. Al mismo tiempo, mostraría que, en este punto, el desacuerdo acerca de la normatividad jurídica gira en torno a la posibilidad de fragmentación del razonamiento práctico y, específicamente, si las razones últimas son siempre de carácter moral.

Un segundo argumento al que recurre Sahuí para fundamentar la normatividad del derecho apunta a su dimensión epistémica. Este argumento se apoya en la tesis defendida por Nino de que las decisiones democráticas gozan del status de "presunciones epis-

12 Sahuí Maldonado, "Positivismo y concepción argumentativa del Derecho", op. cit., p. 63.

13 Esta tesis de la diferenciación entre discursos morales y ético-políticos por desarrollada por Habermas en Habermas, Jürgen, Facticidad y Validez. Sobre el Derecho y el Estado democrático de derecho en términos de teoría del discurso (trad. Manuel Jiménez Redondo), Madrid, Trotta, 1998; Id. Aclaraciones a la ética del discurso (trad. José Mardomingo), Madrid, Trotta, 2000, pp. 109-126; y Id. Verdad y Fustificación. Ensayos filosóficos (trad. Pere Fabra y Luís díez), Madrid, Trotta, 2002, pp. 83-103. 
témicas". ${ }^{14}$ Las personas tienen razones - a saber: la superioridad epistémica del derecho democrático- ${ }^{-}$para obedecer al derecho por encima incluso de sus creencias morales más firmes. ${ }^{15}$ Pero, ¿presunciones epistémicas acerca de qué? Si el objeto de la misma es un enunciado empírico (pragmático, en términos habermasianos), estamos ante una presunción de verdad de carácter instrumental o técnico, en todo caso, secundaria respecto de fines los ético-políticos o morales a los que sirve.

Como es sabido, no es éste el sentido de la tesis de Nino, que se refiere a una presunción práctica o moral. Pero, entonces, si se trata de una presunción epistémica a favor de la corrección moral de las decisiones democráticas - fundada no en el mero agregado de opiniones coincidentes, sino en la racionalidad del proceso de deliberación que precede a la toma de decisiones-, la razón que un individuo consciente de sus limitaciones epistémicas en materia moral tiene para obedecer el derecho democrático es la mayor probabilidad de aproximarse a la corrección moral. ¿No es esto, por sí misma, una razón moral? Por otra parte, el argumento de la presunción epistémica sólo es predicable de un tipo específico de normas: el derecho democrático; ¿supone esto que la normatividad del derecho sólo es predicable de este tipo de normas?

Esto es lo que parece sugerir el propio Sahuí cuando sostiene que "[d] esde esta perspectiva esto significa que puede llegar a haber muy buenas razones, en el sentido de razones internas de las personas, para obedecer el derecho sin recurrir a la moral. Lo que por su-

14 Nino, Carlos Santiago, "La paradoja de la irrelevancia moral del gobierno y el valor epistemológico de la democracia”, en Id., El constructivismo ético. Madrid, Centro de Estudios Constitucionales, 1989, pp. 111-133, aquí p. 129.

15 "Dicho deber como siendo auténtico podría ser internamente apreciado en un individuo consciente de sus limitaciones epistémicas, que esté dispuesto en consecuencia a revisar sus creencias morales, aún las más firmes, cuando se halle ante normas cuya legitimidad democrática no haya sido controvertida o respecto de la cual no quepan a priori dudas" (Sahuí Maldonado, "Positivismo y concepción argumentativa del Derecho", op. cit., p. 63). 
puesto no significa que todo derecho por su sola vigencia merezca esa deferencia por parte de sus destinatarios". ${ }^{16}$ Pero, si la mera vigencia del derecho no es merecedora de la obediencia por parte de los destinatarios, ¿en qué consistiría la normatividad específica del derecho?

Como he sostenido más arriba, creo que las razones de tipo epistémico pueden ser vistas como dependientes de razones morales. Ciertamente, ni cuando deriva de los valores y principios público-políticos, ni cuando lo hace de la superioridad epistémica del derecho democrático, el deber de obediencia al derecho descansa en el valor moral de las normas jurídicas particulares; o dicho de otro modo, la normatividad del derecho no depende de que las normas jurídicas expresen un deber que, además de jurídico, es también moral; pero esto no quiere decir que la normatividad del derecho no descanse en un trasfondo moral o, directamente, en razones morales, que es lo que parece sostener Bulygin. Tanto los principios público-políticos liberales, como las presunciones epistémicas, expresan valores morales -formales-, tales como la interdicción de la arbitrariedad, la igualdad de trato, la seguridad jurídica, la racionalidad epistémica en asuntos prácticos que pueden afectar a los intereses de las personas, etc.

Hasta aquí los comentarios a los argumentos en defensa de la tesis de la normatividad jurídica no dependiente de la moral. La segunda línea de argumentación de Sahuí va dirigida a poner de manifiesto la dificultad de una normatividad fundada en la moral. La primera razón es que la moral está lejos de ser "un dominio transparente e indisputado que permita resolver los problemas que surgen al juzgarse la justicia de una norma, en particular; o del orden jurídico, visto globalmente". ${ }^{17}$ De esta opacidad de la moral resultarían dos conclusiones. En primer lugar, que parece contra-

16 Sahuí Maldonado, "Positivismo y concepción argumentativa del Derecho", op. cit., p. 64 .

17 Ibidem. 
dictorio, especialmente si se sostiene una postura escéptica en materia moral, defender -como hace Bulygin- que la normatividad sea una noción moral y, al mismo tiempo, sostener una concepción formal de la justificación jurídica. Ambas cosas parecen no encajar; no queda claro qué signifique justificar jurídicamente una decisión, si se defiende el modelo silogístico, y, a la vez, se niega normatividad propia al derecho, convirtiendo la normatividad en una noción tributaria de la moral, como si la justificación jurídica nada tuviese que ver con la obligatoriedad de las premisas normativas de las que se obtiene la conclusión, ni de la conclusión misma. Creo, por un lado, que se puede ser un escéptico o relativista moral, en el sentido de no admitir la existencia de una moral objetiva o de procedimientos que puedan conducirnos a verdades morales siquiera relativas o dependientes de tales procedimientos y, al mismo tiempo, sostener que las únicas razones para actuar son razones de índole moral subjetivas (cada quien las suyas); esto es, se puede ser un escéptico desde el punto de vista externo, negando la existencia de deberes morales objetivos, y un moralista desde el punto de vista interno. Pero, por otro lado -y aquí creo que lleva razón Sahuí-, difícilmente casa esto con una concepción formal de la justificación jurídica. Como se apuntaba al principio del trabajo, la defensa del modelo silogístico está basada en los principios políticos del liberalismo, y el modelo silogístico es condición necesaria para la realización de dichos principios. Y si, en virtud de esos principios y valores políticos, la justificación jurídica puede presentarse bajo un prisma formalista, entonces, efectivamente, también debería poderse justificar la normatividad del derecho sobre esa "moral liberal" (la denominación puede resultar problemática, pero no especialmente a los efectos que estamos hablando), salvo que el concepto de justificación no guarde ninguna relación con la noción de razones para la acción.

La segunda cuestión tiene que ver con las dificultades epistémicas concernientes a la corrección moral. En mi opinión, estas dificultades - por una parte, innegables, y por otra parte, minimizables- no 
representan una objeción insalvable para poder hablar de la normatividad de la moral. Si las normas morales son en algún sentido razones para la acción, entonces, el hecho de que puedan existir discrepancias entre sujetos con distintas convicciones morales no cambia las cosas. Aquí habría que distinguir, por un lado, entre las razones de cada quien, que pueden ser correctas o no, y, por otro lado, nuestro concepto de justificación. Esta segunda cuestión no se ve afectada por el pluralismo moral como hecho dado. Cuando los defensores de una concepción material de la justificación sostienen que las razones justificatorias últimas son razones morales, no están pensando en las creencias morales de cada individuo. Entiendo este tipo de afirmación como una tesis analítica o conceptual acerca de qué significa justificar en un contexto práctico (esto es lo que entiendo como conexión justificativa) y qué significa que la norma general que sirve de premisa normativa en el razonamiento sea correcta, bien porque su contenido expresa un deber moral objetivo (corrección de primer orden), bien porque existan razones, como principios políticos o presunciones epistémicas, para considerarla, ya sea prima facie o de forma definitiva, como un deber moral (corrección de segundo orden). Obviamente, puede ocurrir que dos individuos recurran a normas morales distintas para justificar decisiones contrarias respecto de un mismo problema práctico, sin embargo, esto no destruye la conexión justificativa, puesto que ambos hacen uso de normas morales; únicamente pone de manifiesto que la moral es un dominio controvertido en el mundo real.

Sin embargo, el argumento de Sahuí es eminentemente normativo; no responde a la pregunta de qué entendemos por justificación (en el sentido de acometer una reconstrucción conceptual, si vale decirlo así), sino que rechaza que la moral deba constituir la única fuente de normatividad, dada su opacidad ${ }^{18} \mathrm{y}$, por tanto, que la

18 De hecho, la justificación discursiva del derecho encuentra en los déficits cognitivos estructurales de la moral uno de sus argumentos centrales; vid. Alexy, Robert, "Diskurstheorie und Menschenrechte", en Id., Recht, Vernunft, Diskurs, 
noción de justificación jurídica deba depender de razones morales. Mientras los defensores de la concepción material tratan de identificar qué razones pueden clausurar un razonamiento práctico, porque no se pueda ir más allá en la exigencia de pedir y dar razones, Sahuí se pregunta, en cambio qué razones deben clausurar un razonamiento práctico en contextos jurídicos, dada nuestra ignorancia o incapacidad para acceder a verdades morales o, al menos, dado el hecho cierto y constatable de la discrepancia moral en las sociedades modernas.

Una última cuestión. Con la intención de evitar que su posición sea asociada con el positivismo ideológico, Sahuí - que se alinea expresamente con el positivismo metodológico- sostiene lo siguiente:

El positivista metodológico auténtico tendría que detenerse en la mera delimitación de los ámbitos moral y jurídico, y dejar que en cada caso los individuos deliberen acerca de cuál debe prevalecer en cada caso, y nada más. Las nociones de razones "concluyentes" o "últimas" contienen criterios evaluativos y no descriptivos, y por tanto no debieran ser empleadas con ligereza por un positivista. ${ }^{19}$

En efecto, consecuentemente con el planteamiento anterior, se niega la existencia de una obligación moral de obediencia al derecho; de hecho, gran parte del razonamiento está enfocado a buscar otro tipo de razones (políticas, epistémicas) distintas a las razones morales en las que fundamentar la normatividad del derecho, su fuerza vinculante. Pero es, precisamente, este empeño en fundamentar la normatividad del derecho lo que resulta sorprendente en un positivista metodológico; ${ }^{20}$ si se trata únicamente de delimitar

Frankfurt am Main, Suhrkamp, pp. 127-164, aquí p. 144; Id. Teoría de la argumentación jurídica, op. cit., p. 150; y Habermas, Jürgen, Factividad y Validez, op. cit., pp. 557-558.

19 Sahuí Maldonado, "Positivismo y concepción argumentativa del Derecho", op. cit., p. 67.

20 Cfr. Bulygin, Eugenio, El positivismo jurídico, México D. F., Fontamara, 1997, pp. 96 y ss. 
los ámbitos moral y jurídico y dejar que los sujetos deliberen en cada caso, ¿por qué ese esfuerzo en justificar la relevancia práctica del derecho?

\section{EL PRINCIPIO DE UNIDAD DE RAZÓN PRÁCTICA}

La cuestión que centra este apartado, la unidad de razonamiento práctico, guarda estrecha relación con la tratada en el apartado anterior. Nos ocuparemos en primer lugar del carácter último y excluyente de las razones morales. Al respecto, Sahuí sostiene lo siguiente:

He de confesar que no entiendo bien cómo ciertas razones y principios valorativos puedan ser calificados a priori como "morales", y en este sentido, ser apreciados como "últimos". Es decir, no veo cómo determinadas normas y juicios de valor que aparecen eventualmente en un discurso, siempre de la mano de un individuo o grupo particular, puedan pretender para sí mismas el atributo de ser razones concluyentes. Resulta obvio que no basta que cualquiera de las partes en un discurso práctico afirme que las suyas son razones morales, y que las de su contrario son razones inmorales, o que tan sólo son razones jurídicas, políticas, religiosas, prudenciales, etc. ${ }^{21}$

Creo que aquí se plantean dos cuestiones, si no distintas, sí diferenciables. La primera tendría que ver con las pretensiones formuladas por los participantes en un discurso práctico; la segunda, con el problema de cuándo estamos ante una razón moral. En cuanto a la primera, el hecho de que las razones sean hechas valer en los discursos por personas reales que, posiblemente, si no probablemente, son falibles y pueden estar equivocadas es insalvable. Y ello en tanto que, con independencia de en qué consista la verdad o la corrección moral y con todas las reservas que se quieran relativas a la falibilidad del saber humano, especialmente en los asuntos morales, el

21 Sahuí Maldonado, "Positivismo y concepción argumentativa del Derecho", op. cit., p. 68. 
acceso a la verdad o la corrección moral no puede suceder de otro modo que a través del lenguaje en un discurso real. Incluso en el caso de que existiera un consenso universal acerca de la corrección de una decisión jurídica, siempre derivará de las opiniones o de las aspiraciones de uno o varios individuos o de uno o varios grupos, quienes las hacen valer en un discurso consiguiendo la adhesión de todos los afectados, que son persuadidos mediante razones. Que estas razones presentadas por los participantes en el discurso sean calificados a priori como morales y, por tanto, como razones últimas o excluyentes es algo consustancial al propio funcionamiento del discurso; lo esencial aquí no es que los participantes crean que tienen razones morales para sustentar una decisión - ¿qué otra cosa puede pretender quien afirma o defiende una razón determinada?--, sino su disposición a ser persuadidos por las razones de otros participantes en el discurso. Dicho con otras palabras, el problema no es la pretensión de corrección, sino que ésta vaya acompañada de una pretensión de infalibilidad. ${ }^{22}$

La perplejidad manifestada en el párrafo anterior va más allá y plantea todavía una segunda cuestión: cuándo estamos ante una razón moral; o cabría decir, más bien, si eso es algo que pueda dilucidarse previamente al desarrollo de un discurso práctico. De este modo es como entiendo las dudas de Sahuí acerca de que razones y principios valorativos puedan ser calificados a priori como morales, así como la negativa a aceptar como razones morales cualesquiera razones esgrimidas por los participantes en el discurso. Si rechazamos -y creo que así debe ser- la perspectiva subjetiva y meramente descriptiva según la cual son razones morales las razones últimas que los individuos esgrimen para justificar sus acciones, sólo queda intentar responder a esta pregunta desde un punto de vista objetivo

22 Sobre esto, vid. Lafont, Cristina, The Linguistic Turn in Hermeneutic Philosophy (trad. José Medina), Cambridge (Mass.), MIT Press, 1999, en espcial Caps. 5 y 6 [Existe una versión castellana anterior y menos extensa, La razón como lenguaje. Una revisión del "giro lingüistico" en la filosofía del lenguaje alemana. Madrid, Visor, 1993]. 
y normativo, esto es, identificando alguna propiedad que haga de una razón una razón moral. En mi opinión, esa propiedad no es otra que la universalizabilidad. ${ }^{23}$ En efecto, no cualquier razón es una razón moral, sino sólo aquellas que son universalizables, lo cual parecería confirmar las dudas acerca de que razones y principios valorativos puedan ser calificadas como morales previamente a su consideración discursiva y su aceptabilidad racional. ${ }^{24}$ Todo esto parece conducir a la conclusión de que no puede haber razones morales erróneas o equivocadas: o bien una razón es universalizable, o bien no es una razón moral, esto es, sería una razón inmoral, injustificable desde el punto de vista de la universalización (u otro criterio de justificación moral), o una razón contextual, sólo justificable en un contexto valorativo dado: jurídico, político o religioso. Pero, si esto es así, la confluencia entre moralidad y corrección sólo puede hablar a favor de la consideración de las razones morales como razones últimas. En todo caso, la falibilidad de nuestros juicios no puede significar que no existan razones morales, sino que erróneamente consideramos como tales, razones no universalizables.

Pasemos ahora a la cuestión central de este apartado; ¿son las justificaciones contextuales verdaderas justificaciones? Aquí, de nuevo, entra en juego el argumento epistémico, del cual pueden distinguirse dos versiones o variantes: una negativa, que cuestiona que las razones últimas de toda justificación hayan de ser razones morales; y otra, positiva, en defensa de la fragmentación del razonamiento práctico. Veamos la primera:

23 Obviamente, esta es una cuestión altamente controvertida. El principio de universalización es sólo uno entre otros muchos fundamentos de la moral.

24 Aunque se defendiera una interpretación realista del discurso práctico, según la cual las normas o decisiones serían moralmente correctas si de hecho satisfacen los intereses de cada uno, la justificación (aceptabilidad racional) es una exigencia pragmática ineludible para todo aquel que afirme que una norma o una decisión está moralmente justificada. 
En resumen, como cualquier otro orden normativo la moral es un dominio en disputa permanente, y por ende abierto. Su preeminencia en relación con los otros órdenes, si es que alguna tiene, no existe modo razonable de que opere en los discursos reales donde se trata de justificar decisiones prácticas, sobre todo por restricciones epistémicas. ${ }^{25}$

Nadie pone en duda las limitaciones epistémicas en los discursos reales, pero, precisamente por este motivo, dudo que la defensa de la unidad de razonamiento práctico ponga especial énfasis en el cognoscitivismo moral, aunque, desde luego, presuponga su posibilidad. Como he sostenido más arriba, la preeminencia de las razones morales me parece más bien una cuestión conceptual: llamamos razones morales a aquellas razones en las que se detiene el razonamiento, precisamente por esa relación conceptual que se establece entre lo moral y lo correcto.

En opinión de Sahuí, pretender que uno está en disposición de cerrar un discurso práctico es "asumir injustificadamente el rol de un observador completamente objetivo e imparcial"; nadie puede clausurar una discusión práctica "si por tal se entiende blindar una decisión contra toda crítica razonable". ${ }^{26}$ Esto es difícilmente cuestionable, pero no creo que sea a lo que se refieren los defensores del principio de unidad de razonamiento práctico. En realidad, cualquier participante en un discurso pretende que está en lo cierto (si no, no tendrían sentido sus afirmaciones), pero esto no implica, como ya se ha dicho, una simultánea pretensión de infalibilidad. En esto radica la diferencia entre justificación y verdad; $;^{27}$ en otras

25 Sahuí Maldonado, "Positivismo y concepción argumentativa del Derecho", op. cit., p. 68.

26 Ibidem.

27 Para esta distinción en la Filosofía discursiva, vid. Fabra, Pere, Habermas: Lenguaje, Razón y Verdad, Barcelona, Marcial Pons, 2008, Cap. IX; Habermas, Jürgen, Verdad y Justificación, op. cit., pp261 y ss.; Lafont, Cristina, The Linguistic Turn in Hermeneutic Philosophy, op. cit., Cap. 5; y Wellmer, Albrecht, "Was ist eine 
palabras, las razones que justifican una decisión en un discurso real son tenidas (justificadamente) por razones morales, pero, en un discurso posterior, pueden mostrarse falsas o equivocadas. Esta circunstancia modificaría la decisión, que ya no estaría justificada por dichas razones, pero no cambiaría el hecho de que las razones últimas, las que justifican la decisión, son razones morales. En definitiva, la condición última de las razones morales no tiene tanto que ver con el grado de certeza de nuestros juicios morales, que nunca puede ser absoluto, sino con nuestro concepto de justificación y qué entendemos por razón justificatoria, que, obviamente, tiende a identificarse con la idea de corrección, esto es, con algún sentido de la idea de universalizabilidad. ${ }^{28}$

En cuanto a la versión positiva del argumento epistémico, esto es, la defensa de la fragmentación del discurso práctico, Sahuí sostiene que "en un mundo plural y complejo como el actual, sólo bajo el riesgo de confundir y empobrecer las discusiones prácticas, es que puede sostenerse que en relación con cada individuo sea la moral

pragmatische Bedeutungstheorie? Variationen über den Satz 'Wir verstehen eine Sprechakt, wenn wir wissen, was ihn akzeptabel macht'", en Honnet, Axel / McCarthy, Thomas / Offe, Claus / Wellmer, Albrecht (Hrsg.) Zwischenbetragtungen. Im Prozeß der Aufklärung. Fürgen Habermas zum 60. Geburstag, Frankfurt an Main, Surkamp, 1989, pp. 318-370, aquí p. 340.

${ }^{28}$ Bulygin, en cambio, afirma que cuentan como morales las razones que cada persona cree que lo son. Como he argumentado más arriba, esta concepción subjetivista no nos lleva demasiado lejos; si lo que sostiene es que el carácter moral de las razones depende de que alguien las considere suficientes para justificar una decisión o una acción, aunque sean inaceptables, entonces la expresión "tener razones morales" adquiere un sentido exclusivamente descriptivo, donde lo moral explica qué es lo que mueve a la persona a actuar como lo hizo: no por conveniencia, temor o prudencia, sino por sus convicciones - posiblemente, aunque no necesariamente, equivocadas- acerca de lo correcto. Por otro lado, la existencia de los remordimientos es una prueba de que no siempre puede los sujetos encontrar una razón que justifique sus decisiones o acciones. 
el último baluarte de justificación auténtica". ${ }^{29}$ De hecho, dicha fragmentación es un rasgo propio de las sociedades complejas:

Son muchos los dominios práctico-normativos en los que se describen acciones como justificadas o correctas bajo sus propios estándares. Esto representa una ventaja cognitiva y práctica de las sociedades modernas respecto de las tradicionales, en las que cualquier acción discreta continúa siendo evaluada con base en parámetros morales y/o religiosos. ${ }^{30}$

Como he sugerido páginas atrás, me parece que en esta discusión se desarrolla en planos distintos. Quienes defienden la unidad de la razón práctica se preguntan qué significa justificar una norma, una acción o una decisión y concluyen que sólo podemos hablar de justificación si podemos aducir una razón moral (universalizable), independientemente de la dificultad que suponga encontrar dichas razones. Su argumento es conceptual. En cambio, la defensa de la fragmentación de la razón práctica es de naturaleza normativa: dada la pluralidad axiológica y la complejidad funcional de las sociedades modernas, debemos descargar a los sujetos del esfuerzo de justificar moralmente cada una de sus acciones y admitir justificaciones parciales contextuales. Pero, ¿no es ésta una razón moral? Ciertamente, es posible esgrimir otro tipo de razones para aceptar justificaciones parciales o contextuales, por ejemplo, las limitaciones epistémicas de las personas reales, la eficiencia en el funcionamiento de las instituciones o la seguridad jurídica, sin embargo, me parece que todas ellas son razones instrumentales respecto de valores morales últimos. Nino, entre otros, ${ }^{31}$ habló de las "relevan-

29 Sahuí Maldonado, "Positivismo y concepción argumentativa del Derecho", op. cit., p. 69.

3о Sahuí Maldonado, "Positivismo y concepción argumentativa del Derecho", op. cit. p. 70 .

31 Planteamientos muy similares pueden encontrarse en Alexy, Robert, "Juristische Interpretation", en Id., Recht, Vernunft, Diskurs, Frankfurt am Main, Suhrkamp, 1995, pp. 71-93; Peczenik, Aleksander, On Law and Reason, Dordrecht 
cia moral del derecho", poniendo de manifiesto que la existencia de normas jurídicas y de precedentes judiciales no es un dato moralmente irrelevante. La idea, tantas veces repetida, de que el discurso jurídico alcanza en muchas ocasiones un resultado distinto al que se llegaría en un discurso moral parece ignorar esta circunstancia: el derecho no puede ser obviado en el discurso moral, especialmente en un mundo plural axiológicamente y complejo funcionalmente.

Este es el sentido de la concepción alexiana del discurso práctico general. ${ }^{32}$ En realidad, el discurso práctico general opera como meta-discurso en el que son consideradas todas las razones relevantes (morales, políticas, jurídicas, etc.) o los resultados de todos los discursos parciales o especiales. De dicho (meta)discurso práctico general podría resultar que se tuviera por justificada una acción o una norma que de no existir determinadas normas jurídicas no podría tenerse por justificada.

\section{Metaética y teoría del derecho}

El penúltimo apartado analiza la relación entre metaética y teoría del derecho; más concretamente, el problema de si el objetivismo moral es compatible con la tesis de la separación conceptual entre derecho y moral mantenida por el positivismo metodológico. ${ }^{33} \mathrm{Se}-$ gún Sahuí, "lo que un positivista opine sobre la moral es irrelevante para el propósito de explicar y comprender el derecho"; ${ }^{34}$ o sea,

/ Boston / London, Kluwer, 1989; Id. "Dimensiones morales del derecho" (trad. Juan A. Pérez Lledó), Doxa, núm. 8 (1990), pp. 89-109; o Bayón, Juan Carlos, “La racionalidad de dictar y seguir reglas", Doxa, núm. 19 (1996), pp. 143-162.

32 Esto no significa en ningún caso asumir la corrección de la conocida "tesis del caso espacial" (vid. Alexy, Robert, Teoría de la argumentación jurídica, op. cit.).

${ }^{33}$ El hecho de que eminentes positivistas, como Kelsen o Ross, hayan defendido posiciones relativistas o escépticas en materia ética no significa, en modo alguno, la existencia de algún tipo de conexión necesaria entre ambas tesis.

34 Sahuí Maldonado, "Positivismo y concepción argumentativa del Derecho", op. cit. p. 72 . 
que "[s]e puede ser positivista metodológico siendo un objetivista y cognoscitivista en materia práctica". ${ }^{35}$

En este punto, la posición de Bulygin ha cambiado en los últimos años. En un principio, Bulygin defendió la incompatibilidad de la objetividad moral y la tesis de la separación conceptual sobre la base de un argumento bien conocido; a saber, la aceptación de la verdad moral supone la redundancia y superfluidad del derecho. ${ }^{36}$ La crítica de que es objeto por parte de Ricardo Caracciolo ${ }^{37}$ hace que Bulygin cambie de opinión, pero $-\mathrm{y}$ aquí es donde Sahuí se muestra en desacuerdo con Bulygin- al precio de renunciar a toda pretensión de objetividad de las normas jurídicas, ${ }^{38}$ pues dicha objetividad sólo sería predicable de las proposiciones normativas, susceptibles de verdad o falsedad, como aquellas que afirman la

35 Sahuí Maldonado, "Positivismo y concepción argumentativa del Derecho", op. cit. p. 73 .

36 Bulygin lo expone del siguiente modo: "[S]i hay una moral privilegiada, cuyas normas son verdaderas, entonces uno debe hacer lo que esas normas prescriben, y si hay otras normas que prescriben algo incompatible con las normas morales, esto no se debe hacer. Para esta posición sería contradictorio afirmar que, de acuerdo al derecho, p es obligatorio (en el sentido de que uno debe hacer p) y sostener al mismo tiempo que, conforme a la moral, p no es obligatorio o prohibido (uno no debe hacer p). No hay tal cosa como el acto de "hacer p conforme al derecho" o el acto de "hacer p conforme a la moral"; sólo hay actos de hacer $p$ o de no hacer (= omitir). Por tanto, o bien uno debe, o bien uno no debe hacer p.

En este sentido, si "admitir cierto grado de objetividad en las discusiones morales de carácter normativo" significa aceptar que hay verdad moral, la distinción conceptual entre derecho y moral se vuelve insostenible. Más aún, la existencia del derecho (entendiendo por tal el derecho positivo) se torna problemática. ¿Para qué dictar normas jurídicas si ya sabemos lo que debemos hacer?"; Caracciolo, Ricardo, "Entrevista a Eugenio Bulygin”, Doxa, núm. 14 (1993), pp. 499-513; cita en pp. 510-511).

37 Caracciolo, Ricardo, "Realismo moral vs. positivismo jurídico", Analisi e diritto, a cura di P. Comanducci e R. Guastini, 2000, pp. 37-44.

38 "No es que las normas jurídicas positivas pierdan la "normatividad" u "objetividad" del deber si hay normas morales verdaderas, sino que no hay tal cosa como normas jurídicas objetivamente válidas" (Bulygin, El positivismo jurídico, op. cit., p. 118). 
existencia de una norma jurídica, de las cuales no puede derivarse un deber. Como consecuencia de ello, no habría deberes jurídicos objetivos, lo cual es incompatible con la tesis de la normatividad del derecho defendida a lo largo del trabajo de Sahuí.

Mis comentarios van dirigidos a estas tres cuestiones: la primera tiene por objeto la constatación de que en el planteamiento de Bulygin no hay lugar para la existencia de deberes prácticos objetivos de ningún tipo; la segunda es la asimetría entre los enunciados normativos jurídicos y los enunciados normativos morales; y la tercera viene a cuestionar la plausibilidad de la tesis de separación conceptual entre derecho y moral en un escenario hipotético en el que se admitiera la existencia de verdades morales accesibles al conocimiento humano.

La primera de estas cuestiones, la existencia de deberes prácticos objetivos, centró la discusión entre Bulygin y Caracciolo. Para Caracciolo, la contradicción entre los deberes jurídicos y los deberes morales a que se refería Bulygin no era tal, ya que cada uno de estos deberes, de existir, sería objetivo en un sentido distinto: en relación con las normas jurídicas, la objetividad significa pertenencia al sistema jurídico, lo cual depende de hechos más o menos complejos empíricamente comprobables, como, por ejemplo, la existencia de una práctica social; en cambio, la objetividad de las normas morales es equivalente a la verdad, lo que implica su correspondencia con "hechos morales". Así, es perfectamente compatible afirmar que "conforme al sistema jurídico $D$ se debe hacer $p$ " (existe un práctica social que confirma la pertenencia de la obligación de hacer $p$ al sistema jurídico $D$ ) y "conforme a la moral no se debe hacer $p$ " (existe un hecho normativo tal que no se debe hacer $p$ ). Pero Bulygin no se limita a aceptar esta conclusión, sino que la lleva hasta sus últimas consecuencias, negando la existencia de deberes jurídicos objetivos: del enunciado "conforme al sistema jurídico $D$ se debe hacer $p$ " no puede derivarse ningún deber de hacer $p$, puesto que se trata de una proposición normativa, susceptible de verdad o falsedad, 
que únicamente describe la existencia de una norma jurídica. Para derivar una norma de una proposición normativa como la anterior se precisaría una premisa normativa adicional que estableciera la obligatoriedad de obedecer al derecho (Bulygin, 2006: 119). El propio Bulygin advierte la proximidad de esta premisa con la norma fundamental de Kelsen, por lo que podemos denominarla como "premisa fundamental". La existencia de deberes jurídicos objetivos descansaría, entonces, en dicha premisa. De hecho, El trabajo de Sahuí puede verse, siquiera parcialmente, como un intento de fundamentar dicha premisa sobre argumentos no morales, o sea, el intento de justificar la existencia de un deber práctico de obediencia al derecho no reducible a un deber moral de obediencia.

En todo caso, dado que una premisa de este tipo no es una necesidad lógica, la conclusión no puede ser otra que la inexistencia de deberes jurídicos objetivos. Por otra parte, si se mantiene una posición escéptica en relación con la existencia de normas morales, como hace Bulygin, ${ }^{39}$ no cabría hablar de la existencia de deberes objetivos de ningún tipo, ni jurídicos, ni morales.

Con todo, cabría preguntarse si las proposiciones normativas morales exigirían igualmente una premisa fundamental para fundamentar deberes objetivos. Esto nos conduce a la segunda cuestión, la asimetría entre los enunciados normativos morales y los enunciados normativos jurídicos. Según se ha dicho, de un enunciado normativo como "conforme al sistema jurídico $D$ se debe hacer $p$ " no se puede derivar un deber objetivo de hacer $p$; pero, ¿qué ocurre con un enunciado como "conforme a la moral objetiva no se debe hacer $p$ ”? ¿No es también una proposición normativa cuyo objeto es la norma moral que establece que no se debe hacer $p$ ? Si lo es, y esta proposición normativa es verdadera, ¿podemos derivar del mismo un deber moral objetivo sin recurrir a una premisa fundamental

39 Bulygin, Eugenio, El positivismo jurídico, op. cit., p. 119; Caracciolo, Ricardo, "Entervista a Eugenio Bulygin", op. cit., pp. 509-510. 
que estableciera la obligatoriedad de la moral? Si la respuesta es afirmativa, esto es, si el deber de obediencia está implícito en la mera afirmación de las normas morales, la verdad de los enunciados normativos morales, a diferencia de la verdad de los enunciados normativos jurídicos, sería no sólo condición necesaria, sino también suficiente para la existencia de deberes morales objetivos. Me parece que esta asimetría, que tiene que ver con las diferentes condiciones de verdad de cada uno de estos enunciados, si se admite, evidenciaría el carácter último de los deberes morales en el discurso práctico.

Por último, consideremos la distinción conceptual entre el derecho y la moral, admitida la tesis de la objetividad moral en un sentido fuerte, esto es, no sólo ontológico, sino también epistemológico. Aquí quisiera tomar las cosas desde un punto de vista algo distinto a como se ha hecho hasta el momento, pero sin apartarme del argumento de Bulygin reproducido más arriba. La crítica de Caracciolo pretende mostrar que no hay contradicción en afirmar simultáneamente que "conforme al derecho, $p$ es obligatorio" y que "conforme a la moral, $p$ está permitido o prohibido", pero deja fuera otras cuestiones importantes. De hecho, Bulygin no sólo plantea el problema de la contradicción entre sistemas normativos, sino que aprecia también un problema pragmático de unidad de acción, es decir, que con independencia de que dos órdenes normativos establezcan deberes distintos cuyo cumplimiento es incompatible, la acción humana sólo puede ser una ("sólo hay actos de hacer $p$ o de no hacer"); e, igualmente, sostiene que si se acepta la existencia de deberes morales objetivos (verdaderos), la distinción conceptual entre derecho y moral se "vuelve insostenible" y la existencia del derecho se "torna problemática" ${ }^{40}$ Ignoro cuál es el alcance exacto que quiso atribuir a estos términos, pero no creo que tengan nada que ver con la idea de contradicción entre sistemas normativos, sino,

40 Ver nota 34. 
más bien, con sus funciones sociales y, especialmente, con la función social del derecho. No sólo se discute aquí si dos o más órdenes normativos pueden coexistir sin que ello suponga una contradicción lógica; se discute también si, en un escenario como el descrito, en el que las normas jurídicas pueden ser contrarias a las de la moral objetiva, tiene sentido que existan (si es que los deberes jurídicos y las posibles contradicciones con las normas morales están ahí para algo más que para ser identificados por los teóricos del derecho positivistas). La carga de la argumentación corresponde, obviamente, al derecho positivo; como se preguntaba en su momento el propio Bulygin, ¿para qué dictar normas jurídicas si ya sabemos lo que debemos hacer?

El sentido de la separación entre el derecho y la moral puede residir bien en la necesidad para la convivencia humana de un orden normativo objetivo ${ }^{41}$-el derecho positivo- una vez constatadas las deficiencias de la moral para erigirse en dicho orden (por así decirlo, el derecho positivo se desgaja de la moral para generar un orden normativo objetivo o, al menos, más objetivo que la moral); o bien en la necesidad de crear espacios al margen del derecho positivo, que permitan la coexistencia de diversas concepciones axiológicas del mundo (la moral se desgaja del derecho positivo -o si se quiere, éste establece un espacio de no interferencia- para permitir la convivencia de órdenes subjetivos). En el caso de que existiera una moral objetiva accesible al conocimiento humano, el derecho positivo perdería uno de los argumentos más persuasivos -aunque no el único- para justificar su existencia, puesto que no podría presentarse ya como un orden normativo que viene a solventar los déficits de objetividad de la moral. Tampoco podría justificarse la distinción como la creación de un espacio propio para el pluralismo moral, salvo que se admitiera al mismo tiempo algo así como

41 Entendiendo en este caso por "objetivo" un orden normativo cuyos contenidos son determinables independendiente de las preferencias y creencias subjetivas de sus destinatarios. 
un derecho a la cabezonería y la obstinación en el error moral. En fin, si existiera una moral objetiva y ésta fuera accesible al conocimiento, entonces habría que preguntarse muy seriamente por las razones que justifican la existencia del derecho, y, sobre todo, por las razones para obedecer una norma jurídica contraria a la moral (sólo cabrían razones prudenciales, pero si así fuera, la obligatoriedad del derecho y la de la banda de ladrones sería la misma, como sostienen los realistas). Así, en principio, cuanto más transparente y accesible es la moral objetiva, tanto más insostenible se torna la distinción conceptual entre derecho y moral e injustificable la existencia del derecho positivo. No obstante, el argumento epistémico no es el único en que se sustenta la necesidad del derecho positivo; aunque la moral fuera - como es en muchos casos-transparente y accesible, la existencia de normas e instituciones jurídicas puede justificarse en otras razones de tipo motivacional, en tanto que la sanción jurídica refuerza el cumplimiento de las normas, u organizativo, pues no es sino a través del derecho que se hace posible la coordinación y cooperación social necesaria para alcanzar fines moralmente valiosos.

\section{Positivismo JuRídico Y LA CONCEPCIÓN ARguMentativa DEL DERECHO.}

En el último apartado se plantea abiertamente la cuestión de si un positivista puede admitir coherentemente una concepción argumentativa del derecho. Esta pregunta recibe una respuesta positiva en los términos siguientes:

Si se mira de cerca, no hay nada de contradictorio en entender la argumentación como "encadenamiento de proposiciones" y simultáneamente en admitir la inclusión de "aspectos materiales y pragmáticos". (...) La divergencia, entonces, que por supuesto no es menor, me parece que está en los lugares en que cada uno de ellos estima que es válido buscar dichas proposiciones, de modo 
que se les atribuya solidez y firmeza. Mientras Bulygin diría que únicamente el derecho es fuente de tales proposiciones, Atienza y Nino sostendrían que la moral también lo es. ${ }^{42}$

Tengo mis dudas de que esa divergencia no sea relevante a la hora de calificar como compatibles el positivismo metodológico y la concepción argumentativa del derecho. Muchos de los rasgos atribuibles a la concepción argumentativa ${ }^{43}$ son difícilmente compatibles, si no manifiestamente contradictorios, con las tesis mantenidas por el positivismo metodológico, como el debilitamiento de la distinción entre el lenguaje descriptivo y prescriptivo, la reivindicación del carácter práctico de la teoría del derecho o el principio de unidad de razonamiento práctico, que está en la base de la conexión justificativa entre el derecho y la moral. ${ }^{44}$ No obstante, comparto la sensación de que la divergencia puede ser más teórica que práctica, en el sentido de que ambas concepciones acabarían admitiendo casi las mismas decisiones como justificadas jurídicamente, al menos en circunstancias no excepcionales. Y ello, porque también desde el punto de vista de una concepción argumentativa del derecho hay buenas razones (seguridad jurídica, racionalidad teleológica, presunción epistémica a favor del derecho democrático, etcétera) para obedecer al derecho positivo.

42 Sahuí Maldonado, "Positivismo y concepción argumentativa del Derecho", op. cit., p. 78.

43 Atienza, Manuel, El derecho como argumentación. Concepciones de la argumentación, Barcelona, Ariel, 2006, pp. 55-6

44 Esta conexión se manifiesta también como la exigencia de aceptabilidad (Aarnio) o razonabilidad (Alexy) de las decisiones jurídicas; sobre esto, vid. Aarnio, Aulis, Lo racional como razonable. Un tratado sobre la justificación jurídica (trad. Ernesto Garzón Valdés), Madrid, Centro de Estudios Constitucionales, 1991; y Alexy, Robert, "The Reasonableness of Law", en Bongiovani, G. / Sartor, G. / Valentini (eds.), Reasonableness and Law. Dordrecht / Heidelberg / London / New York, Springer, 2009, pp. 5-15. 


\section{Fuentes}

AARnio, Aulis, Lo racional como razonable. Un tratado sobre la justificación jurídica (trad. Ernesto Garzón Valdés), Madrid, Centro de Estudios Constitucionales, 1991.

Alexy, Robert, Teoría de la argumentación jurídica. La teoría del discurso racional como teoría de la fundamentación jurídica (trad. Manuel Atienza / Isabel Espejo), Madrid, Centro de Estudios Constitucionales, 1997.

"Juristische Interpretation", en Id., Recht, Vernunft, Diskurs, Frankfurt am Main, Suhrkamp, 1995, pp. 71-93.

"Diskurstheorie und Menschenrechte", en Id., Recht, Vernunft, Diskurs. Frankfurt am Main, Suhrkamp, 1995, pp. 127-164.

"The Reasonableness of Law", en Bongiovani, G. / Sartor, G. / Valentini (eds.), Reasonableness and Law, Dordrecht / Heidelberg / London / New York, Springer, 2009, pp. 5-15.

Atienza, Manuel, "Eugenio Bulygin y la teoría de la argumentación jurídica", en Moreso, J. J. / Redondo, M. C. (eds.), Un diálogo con la teoría del derecho de Eugenio Bulygin, Barcelona, Marcial Pons, 2007, pp. 39-49.

BAYón, Juan Carlos, "La racionalidad de dictar y seguir reglas", Doxa, núm. 19 (1996), pp. 143-162.

"Bulygin y la justificación de las decisiones judiciales: la parte sorprendente", en Moreso, J. J. / Redondo, M. C. (eds.), Un diálogo con la teoría del derecho de Eugenio Bulygin, Barcelona, Marcial Pons, 2007, pp. $137-152$.

Bulygin, Eugenio, El positivismo jurídico. México D. F., Fontamara, 2006.

"Manuel Atienza: análisis conceptual versus teoría de la argumentación jurídica", en Moreso, J. J. / Redondo, M. C. (eds.), Un diálogo con la teoría del derecho de Eugenio Bulygin, Barcelona, Marcial Pons, 2007, pp. 173-180.

Caracaiolo, Ricardo, "Entrevista a Eugenio Bulygin", Doxa, núm. 14 (1993), pp. 499-513. 
"Realismo moral vs. positivismo jurídico", Analisi e diritto, a cura di P. Comanducci e R. Guastini, 2000, pp. 37-44.

Fabra, Pere, Habermas: Lenguaje, Razón y Verdad, Barcelona, Marcial Pons, 2008.

Habermas, Jürgen, Aclaraciones a la ética del discurso (trad. José Mardomingo), Madrid, Trotta, 2000.

Facticidad y Validez. Sobre el Derecho y el Estado democrático de derecho en términos de teoría del discurso (trad. Manuel Jiménez Redondo), Madrid, Trotta, 1998.

Verdad y Fustificación. Ensayos filosóficos (trad. Pere Fabra / Luis Díez), Madrid, Trotta, 2002.

KocH, Hans-Joachim / Rußmann, Helmut, Furistische Begründunslehre. Eine Einführung in Grundprobleme der Rechtswissenschaft, München, Beck, 1982.

Lafont, Cristina, The Linguistic Turn in Hermeneutic Philosophy (trad. José Medina), Cambridge (Mass.), MIT Press, 1999.

Laporta, Francisco, "Para Eugenio Bulygin", en Moreso, J. J. / Redondo, M. C. (eds.), Un diálogo con la teoría del derecho de Eugenio Bulygin, Barcelona, Marcial Pons, 2007, pp. 33-37.

Nino, Carlos Santiago, "La paradoja de la irrelevancia moral del gobierno y el valor epistemológico de la democracia", en Id., El constructivismo ético, Madrid, Centro de Estudios Constitucionales, 1989, pp. 111-133.

Pegzenik, Aleksander, On Law and Reason, Dordrecht / Boston / London, Kluwer, 1989.

"Dimensiones morales del derecho", Doxa, núm. 8 (1990), pp. 89-109.

Radbruch, Gustav, "Gesetzliches Unrecht und übergesetzliches Recht”, en Id. Gesamtausgabe (Bd. 3), Heidelberg, C.F. Müller, 1990, pp. 83-93.

Sahuí Maldonado, Alejandro, "Positivismo y concepción argumentativa del Derecho. Un alegato a favor de su compatibilidad", en Maurízio Zanotelli (Coord.) Teoría de la argumentación jurídica, Curitiba, Juruá, 2015, pp. 51-81. 
Wellmer, Albrecht, "Was ist eine pragmatische Bedeutungstheorie? Variationen über den Satz 'Wir verstehen eine Sprechakt, wenn wir wissen, was ihn akzeptabel macht'”, en Honnet, Axel / McCarthy, Thomas / Offe, Claus / Wellmer, Albrecht (Hrsg.) Zwischenbetragtungen. Im Proze $\beta$ der Aufklärung. Jürgen Habermas zum 60. Geburstag, Frankfurt an Main, Surkamp, 1989, pp. 318-370. 